\title{
COMUNICAÇÃO ENTRE MÃE HIV+ E FILHO À LUZ DA TACÊSICA EM AMBIENTE NATURAL E EXPERIMENTAL ${ }^{a}$
}

\author{
Communication between HIV+mother and child in the light of kinesics in a natural and \\ experimental environment
Comunicación entre madre VIH+e hijo a la luz de la kinésica en ambiente natural y experimental

Marli Teresinha Gimeniz Galvão ${ }^{1}$

Ivana Cristina Vieira de Lima

Larissa de Fátima Pontes Aguiar ${ }^{3}$

Nathália Lima Pedrosa ${ }^{4}$

\section{RESUMO}

A tacêsica é a forma de expressão da comunicação não verbal relacionada ao toque ou tato, desvelando-se como importante modo de expressão no relacionamento das mães com os bebês. Objetivou-se comparar a comunicação tacêsica entre mãe HIV positivo e seu filho, em ambiente natural e experimental, durante os cuidados maternos do banho e da troca. Filmagens dos cuidados foram realizadas nos dois ambientes e analisadas de forma descritiva por peritos em comunicação. Apesar das similaridades da utilização da tacêsica em ambiente natural e experimental, nos aspectos relativos à localização, intensidade e frequência do toque, a comunicação mediada pelo toque demonstrou ser executada de modo incipiente, sobretudo no ambiente natural. Assim incentiva-se orientar e motivar as mães para ampliar e incrementar os toques durante os cuidados com os filhos com vistas a estimular precocemente a ampliação do vínculo com seu filho e proporcionar o desenvolvimento cognitivo e relacional do bebê.

Palavras-chave: HIV-1. Criança.Comunicação. Enfermagem.

\begin{abstract}
Kinesics is the way non-verbal communication is expressed, related to touch. It reveals to be an important expression mode in the relationship between mothers and infants. The goal was to compare kinesics communication between an HIV + mother and her child, in a natural and an experimental environment, during maternal care for bathing and diaper change. Care was filmed in both environments and descriptively analyzed by communication experts. Despite similarities between the use of kinesics in the natural and experimental environment, regarding touch location, intensity and frequency, touch-mediated communication showed to be executed incipiently, mainly in the natural environment. Thus, mothers should be guided and motivated to expand and increase touch while taking care of their children, with a view to early stimulating the expansion of bonding with their children and enhancing the infants' cognitive and relational development.
\end{abstract}

Keywords: HIV-1. Child. Communication. Nursing.

\section{Resumen}

La kinésica es la forma de expresión de comunicación noverbal relacionada al toque, desvelándose como importante modo de expresión en el relacionamiento de madres con bebés. La finalidad fue comparar comunicación kinésica entre madre $\mathrm{VIH}+$ y su hijo, en ambiente natural y experimental, durante los cuidados maternos del baño y de la higiene. Filmaciones de los cuidados fueron efectuadas en los dos ambientes, seguidas por análisis descriptivo por exper tos en comunicación. A pesar de las similitudes en la utilización de la kinésica en los dos ambientes, en los aspectos de localización, intensidad y frecuencia del toque, la comunicación mediada por el toque mostró ser ejecutada de forma incipiente, sobretodo en el ambiente natural. Se estimula orientar y motivar las madres para ampliar e incrementar los toques durante los cuidados con los hijos para estimular precozmente la expansión del vínculo con su hijo y proveer el desarrollo cognitivo y relacional del bebé.

Palabras-clave: VIH-1. Niño. Comunicación. Enfermería.

\footnotetext{
${ }^{1}$ Enfermeira. Doutora em Doenças Tropicais. Professora do Departamento de Enfermagem da Universidade Federal do Ceará (UFC). Pesquisadora do CNPq. Fortaleza-CE. Brasil. E-mail: marligalvao@gmail.com; ${ }^{2}$ Enfermeira. Mestranda em Enfermagem do Programa de Pós-Graduação em Enfermagem da UFC. Bolsista CAPES Demanda Social. Fortaleza - CE. Brasil. E-mail: ivanacristinalima@gmail.com; ${ }^{3}$ Acadêmica do Curso de Enfermagem da UFC. Bolsista do CNPq-PIBIC-UFC. Fortaleza-CE. Brasil. E-mail: Ialadefatima@gmail.com; ${ }^{4}$ Acadêmica do Curso de Enfermagem da UFC. Bolsista CNPq-PIBIC-UFC. FortalezaCE. Brasil. E-mail: nati.ufc@gmail.com
} 


\section{INTRODUÇÃO}

Em decorrência do diagnóstico de HIV, as medidas de proteção para evitar a transmissão do vírus da mãe ao filho devem se iniciar nos primeiros meses de gestação e perpassam o parto. Ante a situação, a exclusão ao aleitamento materno é um cuidado recomendado por reduzir as interações corporais e comunicativas entre o binômio mãe e filho.

Nesta circunstância, os processos comunicacionais entre mãe e filho, sobretudo nos momentos de aleitamento artificial, ficam prejudicados devido à falta de um contato mais íntimo com o bebê. Isto influencia sobremodo a comunicação e o vínculo entre mãe e filho. ${ }^{1}$

Entre as formas de comunicação, sobressaem a verbal (CV) e a não verbal (CNV). Esta, como uma das primeiras interações entre a mãe e o filho, ocorre com riqueza em expressões como a postura, os gestos, o olhar, o tom de voz e a maneira da mãe tocar o filho. Em face das classificações da CNV, a tacêsica se relaciona ao toque, sua duração, local e tempo de contato, além de formas de aproximação. ${ }^{2}$ Ademais, a distância e a posição mantidas durante a interação entre mãe e filho contemplam a comunicação proxêmica, definida como a forma do indivíduo organizar inconscientemente seu espaço, ${ }^{3}$ sendo aspecto relevante no processo comunicativo materno infantil por favorecer a aproximação e o contato afetivo, visual e tátil.

Na maioria dos relacionamentos humanos, o toque é um aspecto importante, por desempenhar papel decisivo nos atos de encorajar, expressar ternura e mostrar apoio emocional. Como se divulga, os contatos iniciais mediante o toque entre mãe e filho acontecem com intenção de propiciar conhecimento mútuo e estabelecimento de afetos. ${ }^{4}$

Desta maneira, o momento da implementação de cuidados aos recém-nascidos, tais como a alimentação, o banho e todos os outros pormenores do cuidado físico como afagar, acariciar e cantar para o bebê, representa uma oportunidade ímpar para o incremento da interação. Conforme mostra determinada pesquisa, a privação do contato físico pode ocasionar dificuldade, particularmente no aprendizado da leitura, da fala e do andar. ${ }^{5}$

Assim, o toque demonstra ser componente essencial nas interações entre mãe e filho, sendo mais comum no cuidado materno desenvolvido durante o banho proporcionado à criança. Ainda como se divulga, no banho, o bebê revive momentos que Ihe são familiares, pois permaneceu durante a gestação em contato com o meio líquido. Além disso, a constante necessidade de manipulação durante esse cuidado proporciona uma riqueza de interações. Portanto, a mãe deve aproveitar o momento para acariciar o bebê e permitir-lhe sentir-se pertencente a alguém. ${ }^{6}$

Este momento é ainda mais marcante no caso das mães HIV positivo. As relaç̃̃es mãe-filho inseridas no universo do HIV devem ser investigadas com vistas à promoção de cuidado mais eficaz a essa clientela. A enfermagem, na medida em que desenvolve estudos nessa área, favorece melhor enfrentamento ao HIV, principalmente em uma fase marcada por dúvidas e insegurança materna no cuidado dos filhos durante os primeiros anos de vida, quando se estabelece o diagnóstico da infecção ou não do filho.

Apesar de necessárias, pesquisas demonstrando a comunicação entre mãe e filho em face do HIV ainda são incipientes. Associado a isso, o uso de filmagem constitui um modo recente de avaliação nos cenários do cuidado materno. Uma investigação em cenário experimental divulga aspecto inovador sobre os cuidados maternos e a interação mãe-filho, representando uma nova maneira de avaliar a relação entre 0 binômio na vigência do HIV. Entretanto, de acordo com 0 observado em algumas situações de cuidado materno, 0 ambiente experimental pareceu influenciar no comportamento espontâneo da mãe no cuidado com o filho, sugerindo 0 desenvolvimento de investigação em ambiente natural para legitimar esse achado.

Nesta perspectiva, desenvolveu-se este estudo com o objetivo de comparar a comunicação tacêsica entre mãe HIV positivo e seu filho, em ambiente natural e experimental, durante os cuidados maternos do banho e da troca.

\section{MÉTODO}

\section{Estudo descritivo exploratório realizado durante o primeiro semestre de 2010 em Fortaleza, Ceará.}

Participaram seis binômios mãe-filho, cuja mãe tinha conhecimento prévio da infecção pelo HIV e o filho havia nascido sob exposição do vírus. Teve-se como critério de escolha dos binômios: mãe primigesta, com conhecimento do diagnóstico de HIV/AIDS antes do nascimento do filho; filho com até 12 meses de idade, gerado na vigência da infecção materna e sem confirmação diagnóstica da infecção pelo HIV. Como critério de exclusão adotou-se ter participado de estudos anteriores que envolvessem a comunicação.

A disponibilidade para participação do estudo incluiu a autorização prévia de filmagem do cuidado materno, banho e troca do bebê no domicílio da família e da filmagem em data posterior em ambiente experimental.

Como cenário do estudo constaram dois ambientes, 0 natural e 0 experimental. Enquanto o primeiro cenário foi 0 ambiente natural, o segundo foi o experimental. 0 ambiente natural foi constituído dos domicílios de cada um das mães participantes.

Para a coleta de dados, procedeu-se à filmagem utilizando-se uma filmadora digital com amplo aspecto de captação de imagem. No ambiente natural, a filmagem foi conduzida pela pesquisadora com a maior distância possível para não interferir na interação materna. Tomaram-se as imagens dos cuidados nos locais onde a mãe executa cotidianamente o banho e a troca do filho. Por precaução, solicitou-se às mães que não modificassem a organização das 
suas residências e, principalmente, do espaço destinado ao cuidado da criança. Ademais, nenhum tipo de equipamento ou utensílio foi disponibilizado pela pesquisadora para a mãe a fim de desenvolver os cuidados filmados. De modo geral, tevese como intuito permitir a máxima espontaneidade do binômio mãe-filho no seu ambiente natural.

Com vistas a obter os dados no ambiente experimental, este foi captado em data posterior aos cuidados tomados no domicílio. Para isso, montou-se um cenário no Laboratório de Comunicação da Saúde (LabCom_Saúde) da Universidade Federal do Ceará. Esse espaço é destinado a estudos experimentais na área de comunicação nos diversos contextos do cuidado em saúde. Neste ambiente, ocorreram o banho e a troca, mediante disponibilização de utensílios necessários para o desenvolvimento do cuidado materno. Também neste ambiente, a filmadora foi operada por controle remoto de modo a evitar interferência da pesquisadora. Previamente, todas as mães conheceram o laboratório, bem como os equipamentos e cenários para o cuidado.

Para a captação das imagens nos dois ambientes, a mãe foi instruída a desenvolver o cuidado de forma mais natural possível. No domicílio, a mãe ofereceu o banho e a troca em diferentes locais (cozinha, lavanderia e quintal) e utilizou os utensílios disponíveis para esse fim. Todos os cuidados foram realizados no período da tarde. No laboratório, as filmagens foram desenvolvidas nos horários semelhantes aos do domicilio. Neste local foram dispostos diferentes materiais para o banho e a troca da criança. Sob uma bancada retangular medindo um metro de altura, dois metros de comprimento e um de largura, instalou-se do seu lado direito uma banheira de plástico transparente com água na temperatura adequada, sabonete em barra, xampu e toalha. Do lado esquerdo da bancada dispôsse um trocador para a troca de roupa do bebê, fralda de pano e descartável, colônia infantil, talco, roupinhas (camiseta e calça longa de malha). Um brinquedo do tipo chocalho permaneceu na bancada e era possível usá-lo durante os cuidados.

Previamente a mãe foi orientada quanto à possibilidade de alterar a disposição dos utensílios para o desenvolvimento do seu cuidado. As filmagens dos dois cuidados foram efetuadas de modo independente, e não se estabeleceu tempo para a execução destes em nenhum dos ambientes.

Para a mãe se familiarizar com a filmagem, antes do início dos procedimentos a câmera era ligada e iniciava-se a filmagem explicando para ela o funcionamento do equipamento. A referida estratégia foi utilizada para a mãe se acostumar com o equipamento e com o fato de estar sendo filmada. No intuito de evitar imprevistos, os pesquisadores estavam programados para a realização da filmagem em outro dia, caso fosse necessário. Entretanto, todas as filmagens foram concluídas de modo satisfatório na primeira tomada.

Como procedimento anterior à análise de dados, as imagens captadas nos dois ambientes deram origem a um DVD (Digital Video Disc) de cada um dos binômios. Para fins de homogeneização do início e término das cenas dos cuidados, houve uma padronização em virtude de a filmagem sempre começar antes dos cuidados. Para o banho, a imagem iniciou-se quando a mãe direcionou a criança para a banheira, colocandoa na água, sendo interrompida quando a mãe retirava a criança da água. Para a cena da troca, o filme começou quando a mãe colocou a criança sobre uma superfície para enxugá-la. A seguir, ela vestiu o bebê, e o trabalho foi finalizado ao se retirar a criança do local.

As cenas obtidas de cada binômio nos dois ambientes foram analisadas de forma descritiva por três peritos em comunicação. Na escolha dos peritos, adotaram-se os seguintes critérios: a) ter desenvolvido ou desenvolver estudos em comunicação e b) conhecer o referencial teórico. Todos os juízes foram informados sobre os objetivos do trabalho e a forma de avaliação. Eles assistiram ao filme de cada um dos binômios e, após a apresentação, em grupo, implementaram um debate comparativo sobre os aspectos da comunicação tacêsica ocorridos durante o banho e a troca. Como solicitado, a partir da discussão, os peritos registraram em instrumento específico situações que apontavam as semelhanças e diferenças entre os cuidados desenvolvidos no ambiente experimental e no natural.

Para análise, os aspectos da comunicação não verbal (tacêsica), que avalia os toques, foram julgados de acordo com os seguintes critérios: duração do toque (curto, longo), localização do toque, intensidade do toque (leve e firme), tipos de toque (instrumental, expressivo/afetivo, terapêutico, não intencional), frequência (elevada, média, reduzida) e velocidade da ação (rápida, moderada, lenta). ${ }^{2}$

A intensidade do toque é definida como a pressão usada sobre a superfície do corpo durante o toque e varia de acordo com a sensibilidade do local. 0 toque leve revela sutileza, carinho e afeto. Já no toque firme, é usada maior pressão sobre a pele, de modo a prover manipulação e sustentação da criança com segurança.

Entre as formas de toque, o instrumental se constitui como o contato físico deliberado necessário para o desempenho de uma tarefa específica. Citam-se neste aspecto as atividades maternas de cuidado em relação à criança, manifestandose diante da necessidade de esfregar a pele, pôr as fraldas e passar a pomada para prevenção de assaduras. 0 toque terapêutico demonstra uma tentativa da mãe em acalmar o bebê em face de uma reação inesperada dele, como o choro, o soluço e o espirro. ${ }^{6}$ Por sua vez, o toque não intencional é aquele realizado de forma inconsciente e não premeditada.

A frequência refere-se à quantidade de vezes que se toca durante 30 segundos, sendo considerada elevada se ocorrer mais de três vezes, média caso haja dois ou três toques e reduzida se houver apenas um toque ou nenhum. A velocidade da ação está relacionada ao tempo e à forma de realização do toque. Destacam-se os movimentos lentos, pois acalmam a criança e funcionam como acalento. 0 toque rápido pode demonstrar a pressa em finalizar o cuidado. ${ }^{6}$ 
Em decorrência das cenas observadas, os peritos solicitaram inclusão na avaliação do estudo de alguns aspectos envolvidos no cuidado, a saber: duração do cuidado, local de realização, posição adotada pela mãe, oferecimento do brinquedo e risco para queda percebidos nas cenas. Ademais, a idade e o peso dos bebês foram considerados como fatores de influência sobre o tipo e a característica do toque materno.

Como determinado, este estudo foi aprovado pelo Comitê de Ética em Pesquisa da UFC em 3 de abril de 2009 sob protocolo 48/09, e todas as participantes assinaram o Termo de Consentimento Livre e Esclarecido.

\section{RESULTADOS}

Para melhor compreensão dos binômios mãe e filho participantes da pesquisa, segue breve descrição dos aspectos epidemiológicos, socioeconômicos, obstétricos, bem como informações relativas à infecção pelo HIV e à prevenção da transmissão vertical do vírus.

Participaram do estudo seis mães, cuja idade variou entre 18 e 37 anos. A maioria delas era casada (4/6). Três mães autorreferiram cor branca. Apenas uma tinha o segundo grau, enquanto as demais não conseguiram atingir o primeiro grau completo. Com exceção de uma mãe, todas informaram a infecção por via sexual. Quanto à renda familiar, não excedeu a dois salários mínimos, mas duas mães não tinham renda no domicílio. 0 tempo de conhecimento do diagnóstico da infecção pelo HIV variou entre seis meses e três anos. Acerca dos dados obstétricos, houve predominância do número reduzido de filhos $(n=1)$. Entre as mães, três informaram história prévia de aborto. Também, três mães relataram a gravidez como desejada, e apenas duas mães fizeram uso de antirretrovirais na gestação (primeiro e sexto mês da gestação). Das mães que não fizeram uso de antirretrovirais, todas iniciaram AZT $®$ no parto.

No tocante à caracterização das crianças, a idade situou-se entre 2 e 10 meses, com predominância do sexo masculino (4/6). 0 peso aproximado (em quilogramas) dos bebês (B) de acordo com a informação das mães foi, respectivamente, $B 1=7 \mathrm{~kg}, B 2=9 \mathrm{~kg}, B 3=8 \mathrm{~kg}, B 4=4 \mathrm{~kg}$, $B 5=6 \mathrm{~kg}$ e $\mathrm{B} 6=9 \mathrm{~kg}$. A maioria das crianças nasceu de parto cirúrgico (5/6), e somente uma não fazia acompanhamento ambulatorial. Todas as crianças possuíam sorologia inconclusiva no momento da coleta de dados.

A seguir apresentam-se as observações das filmagens obtidas nos dois ambientes. Nos Quadros 1 e 2, há a descrição dos cuidados maternos do banho e da troca nos ambientes natural e experimental de acordo com os aspectos gerais. Nos Quadros 3 e 4, constam informações específicas sobre a comunicação não verbal, no relacionado à tacêsica.

Quadro 1. Descrição de situaç̃es observadas durante os cuidados maternos do banho e da troca nos binômios mãe e filho 1, 2 e 3. Fortaleza, 2010

\begin{tabular}{|c|c|c|c|c|c|c|}
\hline \multirow{3}{*}{$\begin{array}{l}\text { Aspectos da } \\
\text { relação do } \\
\text { binômio }\end{array}$} & \multicolumn{6}{|c|}{ Binômio } \\
\hline & \multicolumn{2}{|c|}{1} & \multicolumn{2}{|c|}{2} & \multicolumn{2}{|c|}{3} \\
\hline & A.N. & A.E. & A.N. & A.E. & A.N. & A.E. \\
\hline \multicolumn{7}{|l|}{ Duração (min) } \\
\hline Banho & 2 & 3 & 5 & 3 & 2 & 3 \\
\hline Troca & 4 & 5 & 2 & 4 & 2 & 5 \\
\hline \multicolumn{7}{|c|}{ Local de realização* } \\
\hline $\begin{array}{l}\text { Banho (ap oio } \\
\text { da banheira) }\end{array}$ & $\begin{array}{c}\text { Mesa da } \\
\text { cozinha }\end{array}$ & Bancada & $\begin{array}{c}\text { Pia da } \\
\text { lavanderia }\end{array}$ & Bancada & $\begin{array}{c}\text { Mesa da } \\
\text { cozinha }\end{array}$ & Bancada \\
\hline Troca & Cama & Bancada & Berço & Bancada & Cama & Bancada \\
\hline \multicolumn{7}{|c|}{ Posição da mãe } \\
\hline Banho & Lateral & Lateral & $\begin{array}{c}\text { Frente a } \\
\text { frente }\end{array}$ & Lateral & Lateral & Lateral \\
\hline Troca & $\begin{array}{c}\text { Frente a } \\
\text { frente e } \\
\text { curvada }\end{array}$ & $\begin{array}{l}\text { Frente a } \\
\text { frente }\end{array}$ & $\begin{array}{l}\text { Frente a } \\
\text { frente }\end{array}$ & $\begin{array}{l}\text { Frente a } \\
\text { frente }\end{array}$ & Lateral & $\begin{array}{l}\text { Frente a } \\
\text { frente }\end{array}$ \\
\hline \multicolumn{7}{|c|}{ Oferecimento do brinquedo } \\
\hline Banho & Não & Não & Sim & Não & Não & Sim \\
\hline Troca & Não & Sim & Sim & Sim & Não & Sim \\
\hline \multicolumn{7}{|c|}{ Risco para queda } \\
\hline Banho & Não & Sim & Não & Não & Não & Não \\
\hline Troca & Sim & Não & Não & Não & Sim & Não \\
\hline
\end{tabular}

A.N.= Ambiente natural; A.E.=Ambiente experimental.

*Em todas as situações do ambiente experimental, o banho ocorreu em banheira apoiada sobre uma bancada e a troca foi efetuada nesta bancada sob um trocador disposto ao lado da banheira. 
Quadro 2. Descrição de situações observadas durante os cuidados maternos do banho e da troca nos binômios mãe e filho 4, 5 e 6 . Fortaleza, 2010

\begin{tabular}{|c|c|c|c|c|c|c|}
\hline \multirow{3}{*}{$\begin{array}{l}\text { Aspectos da } \\
\text { relação do } \\
\text { binômio }\end{array}$} & \multicolumn{6}{|c|}{ Binômio } \\
\hline & \multicolumn{2}{|c|}{4} & \multicolumn{2}{|c|}{5} & \multicolumn{2}{|c|}{6} \\
\hline & A.N. & A.E. & A.N. & A.E. & A.N. & A.E. \\
\hline \multicolumn{7}{|l|}{ Duração (min) } \\
\hline Banho & 4 & 4 & 2 & 1 & 2 & 4 \\
\hline Troca & 7 & 7 & 3 & 6 & 2 & 3 \\
\hline \multicolumn{7}{|c|}{ Local de realizaç̃o } \\
\hline $\begin{array}{l}\text { Banho (apoio } \\
\text { da banheira) }\end{array}$ & $\begin{array}{c}\text { Cadeira no } \\
\text { quintal }\end{array}$ & Bancada & $\begin{array}{l}\text { Mesa da } \\
\text { cozinha }\end{array}$ & Bancada & Chão & Bancada \\
\hline Troca & Cama & Bancada & Cama & Bancada & Cama & Bancada \\
\hline \multicolumn{7}{|c|}{ Posicão da mãe } \\
\hline Banho & $\begin{array}{l}\text { Lateral e } \\
\text { curvada }\end{array}$ & $\begin{array}{c}\text { Frente a } \\
\text { frente }\end{array}$ & Lateral & Lateral & Lateral & Lateral \\
\hline Troca & $\begin{array}{l}\text { Frente a } \\
\text { frente }\end{array}$ & $\begin{array}{l}\text { Frente a } \\
\text { frente }\end{array}$ & Lateral & $\begin{array}{l}\text { Frente a } \\
\text { frente }\end{array}$ & $\begin{array}{l}\text { Frente a } \\
\text { frente e } \\
\text { curvada }\end{array}$ & $\begin{array}{l}\text { Frente a } \\
\text { frente }\end{array}$ \\
\hline \multicolumn{7}{|c|}{ Oferecimento do brinauedo } \\
\hline Banho & Não & Não & Não & Não & Sim & Sim \\
\hline Troca & Não & Não & Não & Não & Sim & Sim \\
\hline \multicolumn{7}{|c|}{ Risco para queda } \\
\hline Banho & Sim & Não & Sim & Não & Não & Não \\
\hline Troca & Sim & Sim & Sim & Sim & Sim & Não \\
\hline
\end{tabular}

Quadro 3. Cuidados maternos do banho e da troca de acordo com os aspectos da comunicação tacêsica dos seis binômios mãe e filho na vigência do HIV (Binômios 1, 2, 3). Fortaleza, 2010

\begin{tabular}{|c|c|c|c|c|c|c|}
\hline \multirow{3}{*}{$\begin{array}{l}\text { Aspectos da } \\
\text { comunicação } \\
\text { tacêsica* }\end{array}$} & \multicolumn{6}{|c|}{ Binômio } \\
\hline & \multicolumn{2}{|c|}{1} & \multicolumn{2}{|c|}{2} & \multicolumn{2}{|c|}{3} \\
\hline & A.N. & A.E. & A.N. & A.E. & A.N. & A.E. \\
\hline \multicolumn{7}{|c|}{ Duração do toque } \\
\hline Banho & Lonqo & Lonqo & Lonqo & Lonao & Lonao & Lonqo \\
\hline Troca & Lonao & Curto & Curto & Curto & Lonao & Curto \\
\hline \multicolumn{7}{|c|}{ Localização do toque } \\
\hline Banho & $\begin{array}{c}\text { Cabeça e } \\
\text { tronco }\end{array}$ & $\begin{array}{c}\text { Cabeça e } \\
\text { tronco }\end{array}$ & Cabeça & $\begin{array}{c}\text { Cabeça e } \\
\text { tronco }\end{array}$ & $\begin{array}{c}\text { Cabeça e } \\
\text { tronco }\end{array}$ & Cabeça \\
\hline Troca & $\begin{array}{c}\text { Membros } \\
\text { inferiores e } \\
\text { aenitália }\end{array}$ & $\begin{array}{l}\text { Tronco e } \\
\text { genitália }\end{array}$ & $\begin{array}{c}\text { Genitália e } \\
\text { membros } \\
\text { inferiores }\end{array}$ & $\begin{array}{c}\text { Genitália e } \\
\text { membros } \\
\text { inferiores }\end{array}$ & $\begin{array}{c}\text { Membros } \\
\text { inferiores e } \\
\text { suberiores }\end{array}$ & Genitália \\
\hline \multicolumn{7}{|c|}{ Intensidade do to que } \\
\hline Banho & Leve & Firme & Leve & Leve & Leve & Firme \\
\hline Troca & Leve & Firme & Leve & Leve & Firme & Firme \\
\hline \multicolumn{7}{|c|}{ Tino de toaue** } \\
\hline Banho & $T$ & 1 & Ie E-A & I e E-A & I e E-A & 1 \\
\hline Troca & 1 & 1 & 1 & 1 & 1 & 1 \\
\hline \multicolumn{7}{|c|}{ Velocidade da acão } \\
\hline Banho & Lenta & Moderada & Moderada & Lenta & Moderada & Moderada \\
\hline Troca & Moderada & Moderada & Rápida & Lenta & Moderada & Rápida \\
\hline \multicolumn{7}{|c|}{ Frequência do toque } \\
\hline Banho & Elevada & Elevada & Elevada & Elevada & Média & Elevada \\
\hline Troca & Média & Elevada & Reduzida & Média & Reduzida & Média \\
\hline
\end{tabular}

* Os aspectos da comunicação tacêsica foram avaliados quanto ao fator que obteve maior destaque durante 0 cuidado. 20

**I=Instrumental; E-A=Afetivo-expressivo; T=Terapêutico. 
Quadro 4. Cuidados maternos do banho e da troca de acordo com os aspectos da comunicação tacêsica dos seis binômios mãe e filho na vigência do HIV (Binômios 4, 5, 6). Fortaleza, 2010

\begin{tabular}{|c|c|c|c|c|c|c|}
\hline \multirow{3}{*}{$\begin{array}{l}\text { Aspectos da } \\
\text { comunicaçãa } \\
\text { tacêsica* }\end{array}$} & \multicolumn{6}{|c|}{ Binômio } \\
\hline & \multicolumn{2}{|c|}{4} & \multicolumn{2}{|c|}{5} & \multicolumn{2}{|c|}{6} \\
\hline & A.N. & A.E. & A.N. & A.E. & A.N. & A.E. \\
\hline \multicolumn{7}{|c|}{ Duração do toque } \\
\hline Banho & Curto & Longo & Curto & Curto & Longo & Longo \\
\hline Troca & Curto & Curto & Curto & Curto & Curto & Curto \\
\hline \multicolumn{7}{|c|}{ Localização do toque } \\
\hline Banho & $\begin{array}{c}\text { Cabeça e } \\
\text { tronco }\end{array}$ & $\begin{array}{c}\text { Cabeça e } \\
\text { tronco }\end{array}$ & $\begin{array}{c}\text { Cabeça e } \\
\text { tronco }\end{array}$ & $\begin{array}{c}\text { Cabeça e } \\
\text { tronco }\end{array}$ & $\begin{array}{c}\text { Tronco e } \\
\text { membros } \\
\text { superiores }\end{array}$ & $\begin{array}{l}\text { Cabeça e } \\
\text { nádegas }\end{array}$ \\
\hline Troca & $\begin{array}{c}\text { Genitália e } \\
\text { membros } \\
\text { inferiores }\end{array}$ & $\begin{array}{c}\text { Genitália e } \\
\text { membros } \\
\text { inferiores }\end{array}$ & $\begin{array}{l}\text { Tronco e } \\
\text { genitália }\end{array}$ & $\begin{array}{c}\text { Genitália e } \\
\text { membros } \\
\text { inferiores }\end{array}$ & $\begin{array}{c}\text { Genitália e } \\
\text { tronco }\end{array}$ & Genitália \\
\hline \multicolumn{7}{|c|}{ Intensidade do toque } \\
\hline Banho & Leve & Leve & Firme & Leve & Leve & Leve \\
\hline Troca & Leve & Leve & Firme & Leve & Firme & Leve \\
\hline \multicolumn{7}{|c|}{ Tipo de toque** } \\
\hline Banho & Te A-E & I e A-E & 1 & le T & 1 & I \\
\hline Troca & 1 & I e A-E & $\mathrm{leT}$ & le T & 1 & 1 \\
\hline \multicolumn{7}{|c|}{ Velocidade da ação } \\
\hline Banho & Lenta & Lenta & Rápida & Moderada & Moderada & Moderada \\
\hline Troca & Moderada & Rápida & Rápida & Rápida & Moderada & Rápida \\
\hline \multicolumn{7}{|c|}{ Frequência do toque } \\
\hline Banho & Elevada & Elevada & Elevada & Média & Média & Média \\
\hline Troca & Reduzida & Elevada & Média & Média & Média & Média \\
\hline
\end{tabular}

Conforme exposto nos Quadros 1 e 2, há diferentes situações evidenciadas durante a observação da interação materna entre os seis binômios. Por exemplo, o tempo dispensado para o cuidado materno do banho no ambiente natural variou de 2 a 5 minutos e para o cuidado no experimental teve duração equivalente ( 1 a 4 minutos). Nas crianças mais novas e com menor peso corporal (p. ex., binômio 4), houve maior tempo para a realização do cuidado, pois as mães se preocuparam em prover melhor sustentação e segurança à criança. Por se tratar de um procedimento mais técnico, que envolve passos predeterminados, como enxugar todo o corpo da criança, passar pomada para a prevenção de assaduras, colocar a fralda, vestir o bebê e penteá-lo, o tempo necessário para a troca foi semelhante nos dois ambientes $(2$ a $7 / 3$ a 7 minutos).

Quanto à posição da mãe em relação ao bebê durante o banho e a troca em ambos os ambientes, não variou, e aconteceu principalmente de duas formas: frente a frente e lateral. A posição frente a frente privilegia a troca de olhares entre mãe e filho e é preterida em detrimento da posição lateral, apesar da viabilidade desta última na realização de movimentos corporais firmes e seguros por parte da mãe, tal como apoiar a criança com um dos braços para esfregar áreas corporais do bebê. ${ }^{6} \mathrm{~A}$ postura lateral também se relaciona à disposição perpendicular da banheira. Ainda nos binômios 1 e 6, as mães apresentaram postura curvada no ambiente natural durante a troca em virtude de esta ter sido executada sobre a cama. No binômio 4, o banho em ambiente experimental ocorreu em banheira apoiada sobre cadeira, fato que exigiu a adoção de postura curvada da mãe. A postura curvada gera desconforto para a mãe no momento do banho e da troca, há possibilidades de desvio do foco, da atenção e do olhar para o bebê, além dos prejuízos ergonométricos. Isso pode interferir na qualidade do toque direcionado ao bebê.

Sobre o oferecimento de brinquedo, foi pouco utilizado em ambiente natural como estímulo para a comunicação, com exceção dos binômios 2 e 6 , nos quais houve estímulo tanto no banho quanto na troca. Em ambiente experimental, em virtude da disposição de brinquedo próximo ao local de cuidado, houve maior oferecimento deste por parte das mães (Quadros 1 e 2). Ainda como se percebeu, o risco para queda foi observado durante a troca em cinco binômios, mesmo em ambiente experimental, onde os utensílios de cuidado estavam todos à disposição das mães. Duas mães (binômios 4 e 5 ) posicionaram as crianças em local desprotegido nos dois ambientes (beirada da bancada e da cama) para alcançar material ou manusear utensilios (fralda, pomada para assadura), distanciaram-se do alcance e da proteção da criança, deixando-a vulnerável a acidente. Outras três mães deixaram seus filhos desprotegidos enquanto procediam à troca de roupa na beirada da cama (Quadro 1e 2).

Como mostram os Quadros 3 e 4 no concernente aos aspectos do toque ocorridos durante a interação materna nos dois cuidados, houve similaridades em relação ao ambiente 
natural e experimental. Ao se avaliar a duração do toque, sobressaíram o curto e o longo, com variação de acordo com 0 local e o momento do cuidado. 0 toque curto se relaciona à velocidade rápida, na qual a mãe toca a criança e logo retira as mãos, sendo predominante nos binômios que executaram o cuidado apressadas em concluí-lo ( 3 e 5). Também se associou à troca de roupa, em especial no momento em que a mãe passa a pomada contra assaduras na genitália dos bebês. No toque longo, a mão da mãe permanece por mais tempo em contato com a superfície do corpo da criança, denotando assim maior atenção, estímulo e afetividade. Predominou durante o banho, nos dois ambientes, principalmente quando era necessário umedecer os cabelos e esfregar as costas das crianças.

Quanto à localização do toque, registraram-se os locais mais evidenciados durante os cuidados maternos; a cabeça e o tronco foram as partes mais tocadas durante o banho e a genitália e os membros inferiores, durante a troca. Em três binômios os locais tocados foram semelhantes no desenvolvimento dos cuidados, enquanto nos outros binômios $(1,3,5)$ houve alteração da localização do toque no cuidado da troca no ambiente natural e experimental.

No referente à intensidade do toque, definida como a pressão usada sobre a superfície do corpo durante o toque, houve a comum necessidade de toque firme para a sustentação da criança. ${ }^{2}$ No entanto, destacou-se a predominância do toque de intensidade leve no ambiente experimental, à exceção dos binômios 1 e 3 , nos quais as crianças estavam agitadas, de forma que as mães adotaram esta intensidade de toque para ajustar as crianças na banheira. Os dois tipos de toque são necessários aos cuidados com o bebê, independente do ambiente, em virtude de proverem segurança, atenção e cuidado vigilante com a criança.

Entre as formas de toque, o instrumental se constitui como o contato físico deliberado indispensável ao desempenho de uma tarefa específica. ${ }^{2}$ Citam-se neste aspecto as atividades maternas de cuidado no tocante à criança, manifestando-se diante da necessidade de esfregar a pele, pôr as fraldas e passar a pomada para prevenção de assaduras. ${ }^{6}$ Este tipo de toque foi predominante nos dois cuidados, tanto no ambiente natural quanto no experimental. 0 toque terapêutico demonstra tentativa da mãe em acalmar o bebê em face de uma reação inesperada dele (p. ex., choro), sendo evidenciado no ambiente natural nos binômios 1,4,5, e no experimental no binômio 5 . Destaca-se, ainda, o toque expressivo-afetivo, utilizado com maior frequência no ambiente experimental (binômios 2 e 4).

Para análise da frequência do toque referente à quantidade de vezes que a mãe tocou o corpo da criança no decorrer do cuidado, obteve-se destaque para as frequências alta e média, em virtude da exigência de intensa manipulação na criança para execução dos cuidados, independentemente do ambiente, achado já esperado. Como percebido, a frequência reduzida associou-se ao menor tempo utilizado para o cuidado (Quadros 3 e 4).

\section{DISCUSSÃO}

A natureza dos cuidados proporcionados pelas mães aos seus filhos durante os primeiros meses de vida tem significado fundamental para a saúde física e mental da criança, seja em curto ou longo prazo. A família, em especial a mãe, é enfatizada como a principal fonte de vínculos na primeira infância. Desempenha papel crucial na redução das chances de alterações psicológicas nas crianças, as quais se estendem para a vida futura. ${ }^{5}$

No domićílio, local de extensão do plano de cuidado em saúde elaborado por profissionais de saúde, o vínculo entre mãe e filho é evidenciado de forma mais transparente, sobremodo mediante momentos de íntima relação, a exemplo daqueles que envolvem os cuidados maternos e seus pormenores. Afirma-se: o enfoque nas ações do sistema de cuidados primários aprimora a função de proteção, contato corporal, alimentação, higiene e bem-estar, refletindo-se positivamente no desenvolvimento da criança. ${ }^{8}$

Deste modo, conhecer o local do desenvolvimento dos cuidados e relacioná-lo ao contexto socioeconômico e estrutural da família é fundamental para a manutenção da saúde dos binômios, em especial aqueles que aguardam o estabelecimento do diagnóstico da infecção pelo HIV, a exemplo das crianças nascidas expostas. ${ }^{9}$

No presente estudo, mediante o cuidado materno do banho e da troca, facilitou-se a promoção da higiene e o bemestar da criança. Soma-se ainda o sistema corporal produzido pelo contato mais íntimo entre mãe e filho via toques ao longo dos cuidados.

Conforme asseverado, o toque tem como componente fundamental a transmissão da afetividade ao longo da interação mãe-filho. A mãe e a criança formam um sistema em virtude das interações, e, neste sistema, o comportamento de cada elemento é frequentemente estimulado pelo comportamento do outro. ${ }^{10}$

Ademais, segundo os resultados deste estudo, a tacêsica, importante elemento da comunicação não verbal para a manifestação de amor, afetividade e desejo na vigência do HIV, ainda é desempenhada de forma incipiente. ${ }^{4}$ Embora identificadas similaridades entre os aspectos da tacêsica no ambiente natural e experimental, o último demonstrou ser mais propício para o desenvolvimento do cuidado de forma tranquila e cuidadosa, além de se relacionar à maior ocorrência de toque de intensidade leve e da variedade de tipos de toque (terapêutico e expressivo-afetivo). Este achado vai ao encontro das hipóteses lançadas em estudo prévio o qual levantou a possibilidade da influência do ambiente experimental no comportamento dos sujeitos da pesquisa, mostrando-se assim distinto do ambiente domiciliar. $^{6}$

Provavelmente o menor destaque para a comunicação tacêsica no ambiente domiciliar ocorra em decorrência da adaptação materna ao ambiente experimental e pelo uso de 
diferentes utensílios que foram oferecidos para o desenvolvimento do cuidado. $E$, acrescenta-se: o fato de estar sendo filmada em um ambiente estranho pode ter levado as mães a desempenharem o cuidado de forma mais cuidadosa de modo a se adaptarem à supervisão do pesquisador.

Citam-se ainda dificuldades observadas quanto à escolha e organização do ambiente de cuidado no âmbito domiciliar. Tais fatores podem interferir na qualidade da comunicação estabelecida entre mãe e filho. ${ }^{3}$ Acerca do local escolhido para o desempenho do cuidado no ambiente natural, predominou o banho de imersão em banheira disposta sobre a mesa da cozinha. Como identificado, a maior parte das mães escolheu a cama para proceder à troca. Contudo, a escolha desses ambientes mostrou-se prejudicial para o desempenho da comunicação de forma geral, incluindo a tacêsica, pois ocasionou o desvio da atenção em relação à criança. A este fato aliaram-se o risco iminente de queda, a adoção de uma postura desconfortável da mãe e a falta de organização/disposição de utensilios para o banho.

Em contraposição, parte desses fatores foi amenizada no ambiente experimental, pois os utensílios estavam ao alcance das mães, portanto, não havia a necessidade de desvio da atenção no cuidado. Além disso, a bancada utilizada para apoio da banheira era ampla e a altura, adequada, facilitando a organização de materiais e a adoção de postura ereta durante o cuidado.

Faz-se pertinente também inter-relacionar as situações socioeconômicas, relacionais e associadas ao HIV ao baixo aproveitamento da comunicação mãe-criança por meio da tacêsica em âmbito domiciliar. Dentre estas, citam-se as precárias condições ambientais, gravidez indesejada, história prévia de aborto, baixa renda familiar, não uso de terapia antirretroviral para prevenção da transmissão vertical e, ainda, a indefinição quanto ao diagnóstico da criança. Pesquisadores afirmam ser impossível separar o desenvolvimento da criança do contexto sociocultural no qual se insere. ${ }^{11}$

Destaca-se: a estimulação da interação com a criança através do uso do brinquedo foi uma estratégia pouco explorada pelas mães, principalmente no ambiente domiciliar. Este é um fator capaz de interferir no aproveitamento do toque expressivo/ afetivo, pois, através da estimulação lúdica, a criança e a mãe se descontraem, sorriem, a criança desenvolve o tato e passa a se sentir segura ao reconhecer o toque de carinho e o afago da mãe. Em corroboração, pesquisadores afirmam que, ao voltar a atenção para objetos, a criança aguça seu sistema tátil e cognitivo, além de dar espaço para a interação materna. ${ }^{12}$

Conforme observado, no presente estudo, a mãe com nível escolar, que lhe conferia maior inserção para leituras e, provavelmente, melhor abstração de diferentes informaç̃̃es, utilizou o brinquedo durante os cuidados no ambiente experimental e natural. Tal situação corrobora o divulgado quando se indica que a escolaridade materna tem impacto sobre o desenvolvimento cognitivo de crianças por meio de fatores como organização do ambiente, expectativas e práticas parentais, experiências com materiais para estimulação cognitiva e variação da estimulação diária. ${ }^{13}$

0 tipo de toque evidenciado durante os cuidados também é outro aspecto a ser destacado. Consoante à literatura, o toque, além de transmitir sentimentos, pode contribuir para reduzir o medo e a ansiedade do outro, proporcionando bemestar físico e psicológico. ${ }^{2}$ Neste estudo, o toque expressivoafetivo revelou-se principalmente no momento do banho no ambiente natural. Em relação ao terapêutico, representado nesta pesquisa pela realização de massagem de relaxamento e pelo acalento durante o choro, foi mais observado e melhor aplicado no ambiente experimental.

De modo geral, a massagem do bebê é uma forma de manifestação comunicativa, produzida pelo toque terapêutico. Induz as crianças a se acalmarem, adquirirem resistência no organismo, tranquilidade no sono e um desenvolvimento psíquico positivo. ${ }^{14}$ No entanto, a maioria das mães não utilizou esta estratégia para amenizar o choro da criança de modo que houve restrito uso do toque terapêutico para alívio do choro ou para tranquilizar a criança.

\section{CONCLUSÕES}

No estudo ora exposto, os achados relativos aos aspectos da comunicação tacêsica surpreenderam os pesquisadores. Apesar da hipótese levantada acerca da maior liberdade e incremento da comunicação no ambiente natural, este demonstrou ser pouco explorado para o desempenho da comunicação tacêsica por meio dos cuidados do banho e da troca de roupa.

Apesar das similaridades da utilização da tacêsica em ambiente natural e experimental, tais como localização, intensidade e frequência do toque, a comunicação mediada pelo toque demonstrou ser executada de forma incipiente, sobremodo no ambiente domiciliar. Como justificativa para este achado, levantam-se algumas possibilidades relativas a aspectos socioeconômicos e à própria infecção pelo HIV, a saber: precárias condições sanitárias e de moradia, gravidez indesejada, história prévia de aborto, idade da mãe, baixa renda familiar, não uso de terapia antirretroviral para prevenção da transmissão vertical e indefinição quanto ao diagnóstico da criança. Aspectos inerentes à comunicação ou ao cunho relacional entre mãe e filho, tais como restrito uso de brinquedo para estimulação e das massagens relaxantes, bem como ambiente inapropriado para o cuidado, também foram apontados como possíveis fatores de interferência na comunicação tacêsica desenvolvida entre mãe e filho na vigência do HIV em âmbito domiciliar. Ainda menciona-se a sobrecarga de atividades que mães portadoras do HIV necessitam desempenhar no lar, fato que limita o tempo dispensado ao cuidado com a criança e pode interferir sobremaneira na qualidade da interação comunicativa estabelecida. 
Diante deste fato, faz-se necessário estimular as mães a manifestarem as diferentes formas de interação com os filhos mediante o uso do toque. Os achados do estudo podem servir de subsídio para a elaboração de programas de treinamento em comunicação não só para as mães portadoras de HIV, mas também para aquelas que desejam incrementar o vínculo com seu filho e proporcionar o desenvolvimento cognitivo e relacional do bebê.

Embora o estudo tenha contribuído para preencher a lacuna referente ao desenvolvimento da comunicação tacêsica entre mãe e filho na vigência do HIV nos diferentes ambientes de cuidados, os pesquisadores indicam limitações. Tais limitações referem-se tanto ao número reduzido de participantes, fator que impossibilita generalizações pertinentes, como ao tipo de método adotado para a avaliação, o descritivo, o qual limitou a precisão nas análises. Destaca-se ainda a lacuna de estudos que utilizem o mesmo objeto de estudo, fator a restringir a discussão dos resultados.

\section{REFERÊNCIAS}

1.Klaus MH, Klaus PH. Seu surpreendente recém-nascido. Porto Alegre: Artmed; 2001.

2. Silva MJPD. Comunicação tem remédio: a comunicação nas relações interpessoais em saúde. São Paulo: Loyola; 2006.

3. Hall ET. A dimensão oculta. Lisboa: Relógio D’água; 1986.

4. Paiva SS, Galvão MTG, Pagliuca LMF, Almeida PC. Comunicação nãoverbal durante cuidados prestados aos filhos por mães com Vírus da Imunodeficiência Humana.Acta Paul Enferm.2010;23(1): 108-213.

5. Zamberlam MAT. Interação mãe-criança: enfoques teóricos e implicações decorrentes de estudos empíricos. Estud Psicol. 2002; 7(3): 399-06.

6. Galvão MTG, Costa E, Lima ICV, Paiva SS, Almeida PC, Pagliuca LMF, A comunicação não-verbal entre mãe e filho na vigência do HIV/AIDS à luz da tacêsica. Esc Anna Nery. 2009; 13(4): 780-85.

7. Paiva SS, Galvão MTG, Pagliuca LMF, Almeida PC. Comunicação nãoverbal mãe/filho na vigência do HIV materno em ambiente experimental. Rev Latino-am Enfermagem. 2010; 18(1): 41-7.

8. Ribas AFP, Moura MLS. Responsividade materna e Teoria do Apego: uma discussão crítica do papel de estudos transculturais. Psicol Reflex Crit. 2004; 17(3): 315-22.

9. Souza AlJ, Silva KM, Silva M. Cuidando de famílias de crianças soropositivas no domicílio. Cienc Cuidado Saude. 2003; 2(2): 177-85. 10. Molcho S. A linguagem corporal da criança. São Paulo: Gente; 2007.

11. Piccinini CA, Moura MLSD, Paes AF. Diferentes perspectivas na análise da interação pais-bebê/criança. Psicol Reflex Crit. 2001; 14(3): 469-85
12. Schwengber DDS, Piccinini CA. Depressão materna e interação mãebebê no final do primeiro ano de vida.Psic Teor Pesq. 2004; 20(3): 23340.

13. Bradley RH, Corwyn RF. Socioeconomic status and child development. Ann Rev Psychol. 2002; 53: 371-99.

14. Fonseca JV, Moreira TMM. Integrando a família no cuidado de seus bebês: ensinando a aplicação da massagem Shantala. Acta sci., Health sci. 2004; 26(1): 35-9.

\section{NOTA}

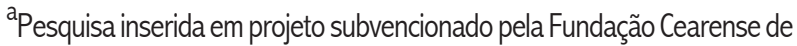
Apoio ao Desenvolvimento Científico e Tecnológico (FUNCAP) e pelo Conselho Nacional de Desenvolvimento Científico e Tecnológico (CNPq). 